\title{
TITLE:
}

\section{A fossil owl monkey from La Venta, Colombia}

$\operatorname{AUTHOR}(\mathrm{S}):$

Setoguchi, Takeshi; Alfred, L. Rosenberger

\section{CITATION:}

Setoguchi, Takeshi ... [et al]. A fossil owl monkey from La Venta, Colombia. Kyoto University overseas research reports of new world monkeys 1988, 6: 1-6

\section{ISSUE DATE:}

1988

URL:

http://hdl.handle.net/2433/199638

RIGHT: 
A fossil owl monkey

from La Venta, Colombia

\author{
Takeshi Setoguchi \\ Primate Research Institute, Kyoto University, \\ Inuyama City, Aichi 484, Japan \\ Alfred L. ROSENBERGER \\ Department of Anthropology, University of Illinois at Chicago, Chicago, \\ Illinois 60680, USA
}

Knowledge of the evolutionary history of living New World anthropoids is limited by a relatively poor fossil record. The discovery in 1986 of a new fossil monkey from the middle Miocene deposits of La Venta, Colombia, 12-15 million years ago (Myr BP), is the first example of a living New World monkey genus appearing in Tertiary rocks. Including anatomical evidence of the dentition and facial skull, it provides an unambiguous link between a Neogene fossil and the owl monkey, Aotus, the only modern crepuscular-nocturnal anthropoid primate. This new form brings to three the number of La Venta fossil monkeys which preserve excellent dentitions sharing extensive similarities with modern genera. All of these species are potentially ancestral to their extant relatives. The La Ventan Aotus is additional support for the idea that the modern platyrrhine radiation includes long-lived genera or generic lineages, some of which may be traceable to the early Miocene, 20 Myr BP.

The broad diversity of the living platyrrhine monkeys of Central and South America has led to the belief that they underwent a very early adaptive radiation ${ }^{1}$. Although the platyrrhine fossil record is still too scarce to evaluate this hypothesis properly, recent reviews of the material $^{2}$ tend to support the idea, bolstered by the identification among the early and middle Miocene species of lineages pertaining to modern genera ${ }^{3,4}$. We report here the discovery of a new species which confirms the early origins of one extant form with some clarity, for it appears to be taxonomically indistinguishable from the owl monkey, Aotus, at the generic level.

Order Primates Linnaeus, 1758

Suborder Haplorhini Pocock, 1918

Infraorder Platyrrhini E. Geoffroy, 1812

Family Atelidae Gray, 1825

Subfamily Pitheciinae Mivart, 1865

Aotus Illiger, 1811

Aotus dindensis, sp. nov.

Type specimen. IGM-KU (lnstituto Nacional de lnvestigaciones Geologico-Mineras [1NGEOMINAS]-Kyoto University) 8601, a left hemimandible with right $\mathrm{I}_{1}$-left $\mathrm{M}_{3}$ and a left maxillary fragment preserving roots of $\mathrm{P}^{3}-\mathrm{M}^{2}$ and the lingual half of $\mathrm{M}^{3}$, all of the same individual.

Hypodigm. Type specimen only.

Locality. Locality 9-86-A in the El Dinde area, probably within the Monkey Unit of the Honda Formation ${ }^{5}$, in the Tatacoa desert, Huila Department, Republic of Colombia.

Age. Middle Miocene, Friasian Land Mammal Age, 12-15 Myr (ref. 6).

Etymology. After El Dinde, the area where the fossil was recovered during the 1986 INGEOMINAS-KU field season.

Diagnosis. Differs from living species of the genus Aotus in the following combination of characters: lower incisors smaller in absolute size and in relation to cheek teeth; $\mathrm{P}_{3,4}$ metaconids smaller and less distinct; premolar trigonids less elevated; $\mathrm{P}_{4}$ entoconid undifferentiated and $\mathrm{P}_{3,4}$ talonids weakly developed; molar trigonids small with metaconid displaced distally, rather than broad and quadrate with transverse cusps; molar metaconids and its crests less prominent (see measurements in Table 1). 
Table 1 Dimensions of Aotus dindensis, IGM-KU 8601

\begin{tabular}{|c|c|c|c|c|c|c|c|c|c|c|c|c|}
\hline & \multirow{2}{*}{$\mathrm{I}_{1}$} & \multirow{2}{*}{$\mathrm{I}_{2}$} & \multirow{2}{*}{$\mathrm{C}$} & \multirow{2}{*}{$\mathrm{P}_{2}$} & \multirow{2}{*}{$\mathrm{P}_{3}$} & \multirow{2}{*}{$\mathrm{P}_{4}$} & \multicolumn{2}{|c|}{$\mathrm{M}_{1}$} & \multicolumn{2}{|c|}{$\mathrm{M}_{2}$} & \multicolumn{2}{|c|}{$M_{3}$} \\
\hline & & & & & & & $\mathrm{Tr}$ & $\overline{\mathrm{T} 1}$ & $\mathrm{Tr}$ & $\overline{\mathrm{Tl}}$ & $\overline{\mathrm{Tr}}$ & $\overline{T 1}$ \\
\hline L & 1.70 & 1.81 & 2.80 & 2.85 & 2.60 & 2.80 & \multicolumn{2}{|c|}{3.52} & \multicolumn{2}{|c|}{3.73} & \multicolumn{2}{|c|}{3.03} \\
\hline B & 2.20 & 2.51 & 3.30 & 2.62 & 2.40 & 2.69 & 2.80 & 3.02 & 2.94 & 2.92 & 2.80 & 2.56 \\
\hline $\mathrm{H}$ & 3.30 & 3.70 & & & & & & & & & & \\
\hline \multicolumn{4}{|c|}{ Mandible height below $\mathrm{M}_{2}$ : } & 10.00 & & & & & & & & \\
\hline \multicolumn{4}{|c|}{ Mandible thickness at $\mathrm{M}_{2}$ : } & 3.35 & & & & & & & & \\
\hline
\end{tabular}

L, mesiodistal; B, buccolingual; $\mathrm{H}$, unworn height; $\mathrm{Tr}$, trigonid; $\mathrm{Tl}$, talonid. All dimensions in $\mathrm{mm}$.

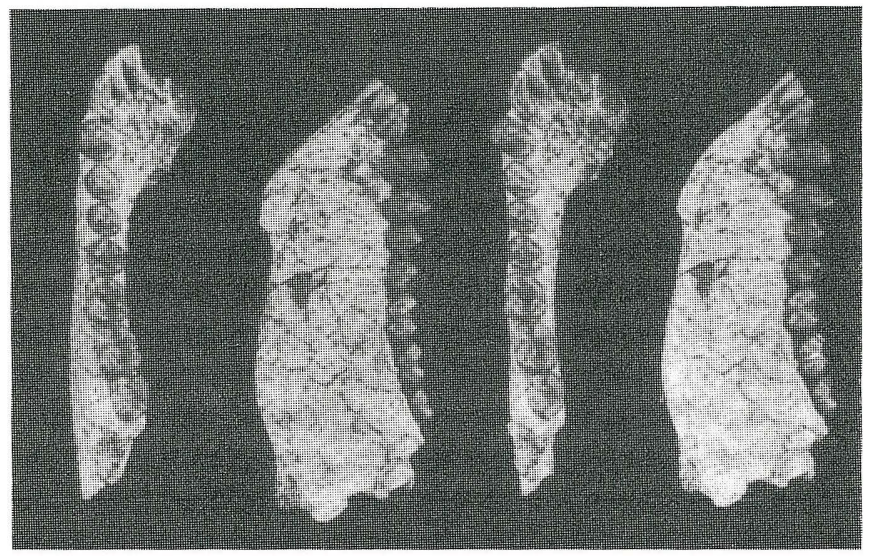

Figure 1 Stereo pairs of Aotus dindensis, n. sp., IGM-KU 8601 (×2). Left pair, occlusal view; Right pair, buccal view.

Description and discussion. So far as is known, A. dindensis shares with the living species of Aotus the same diagnostic suite of dental and mandibular features which distinguishes the latter from other platyrrhine genera (Figs $1-4$ ). This includes, in combination: $I_{1,2}$ with recumbent crowns; $\mathrm{P}_{2}$ with buccolingually compressed, tall and pyramidal crown (in both sexes among the modern species); $\mathrm{P}_{2,3}$ with prow-like preprotocristid; $\mathrm{P}_{3,4}$ not transversely broadened; $\mathrm{M}_{1,2}$ with tall trigonids and faintly differentiated talonid cusps; anterior symphyseal surface slopes forward, is flattened and has moderate lower canine root bosses; inferior border of mandibular corpus sigmoidal, slightly inflected below molars and deepening posteriorly; lingual aspect with large digastric fossa. The only taxonomically distinguishing features, therefore, are those pertinent to the species diagnosis, most notably incisor proportions, and relatively minor aspects of premolar and molar shape.

The maxillary fragment preserves $10 \mathrm{~mm}$ of the dental arcade inferiorly and a portion of the orbital floor superiorly. Essentially, it comprises the compact bone of the maxillary process, securing the roots of the last four postcanines (Fig. 2) and preserving the $\mathrm{P}^{3}$ alveolus and the maxillary tuberosity behind $\mathrm{M}^{3}$. The transverse diameter of this fragment is $11 \mathrm{~mm}$, from the facial surface laterally to its medial limit. The palatal surface preserves small portions of the palatine and the alisphenoidpalatine suture. The greatest dorsoventral thickness from orbital floor to $\mathrm{M}^{1}$ alveolus is $3 \mathrm{~mm}$. Thus the orbital floor was not elevated relative to the toothrow. Only a small anterior portion of the orbital floor appears to have been invaded by maxillary sinus, and there was probably none above the molars posteriorly. 


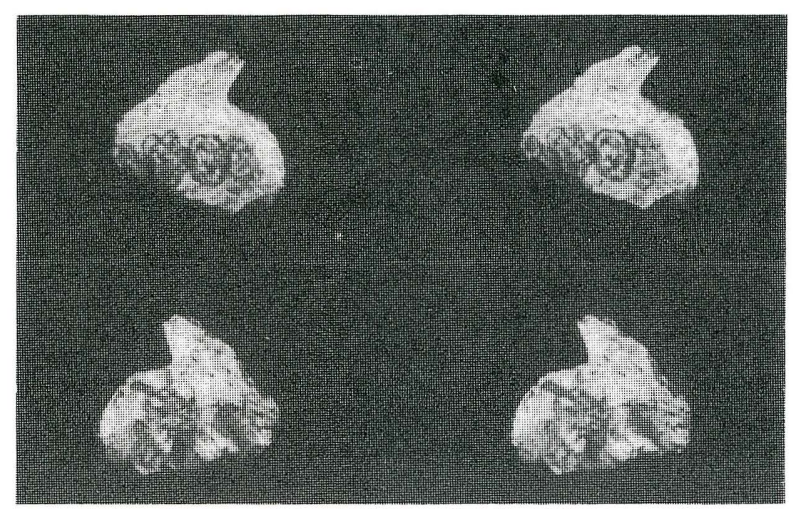

Figure 2 Stereo pairs of Aotus dindensis, n. sp., IGM-KU 8601, maxillary fragment $(\times 2)$. Top, occlusal view; bottom, ventral view.

The thick root of the zygomatic arch lies immediately above the alveolar plane near $\mathrm{M}^{2}$. Its posteroinferior aspect forms a deep concave incisure relative to the lateral surface of the maxillary tuberosity, which further extends for several millimeters posteriorly. This represents the inferior orbital fissure. The size and shape of this opening indicates that the fissure was large in its pristine state, comparable in all details to the anatomy of Aotus which is unique among living anthropoids ${ }^{1,7}$. There are no scars or flattenings on the dorsal surface of the maxilla near the fissure which might indicate ossification or contact with the zygomatic, which forms the posterior seal of the orbit in other anthropoids. Anteriorly, a jagged edge of broken bone marks the position of the ascending lateral wall of the eye socket. This pattern makes it clear that, as in Aotus, the orbitotemporal fenestra of $A$. dindensis was large and the internal aspect of the orbit capacious, conforming to a relatively large eyeball.

Aotus dindensis is dentally more primitive than modern Aotus. The latter is unique among all living and fossil platyrrhines in exhibiting a scoop-like battery of relatively large lower incisors, distinctly absent in the fossil. Additionally, its lower cheek teeth support taller premolar metaconids and taller, more sharply crested trigonids. Whereas living Aotus and $A$. dindensis are probably identical in body size, these morphological contrasts suggest some adaptive differences. The fossil was perhaps less adept in processing foods by premolar and molar puncturecrushing and shearing, implying less insectivory. The smaller incisors indicate a lesser development of harvesting functions, either of fruit husks or insect-infected tree bark. Owl monkeys are mixed feeders, relying on high proportions of fruits and some insects and leaves ${ }^{8}$

The cranial material, although very fragmentary, leaves little doubt that the orbits of Aotus dindensis were enlarged. The eyeballs of living Aotus are very large relative to body size. Their proportions compare with large-eyed nocturnal' strepsirhines ${ }^{9}$, and in both absolute and relative terms their eyes are considerably larger than in other ceboids ${ }^{10}$. The living Aotus is nocturnal throughout most of its geographical range, although its activity pattern involves more daytime and crepusclar hours among populations occupying nontropical southern latitudes ${ }^{11}$. Aotus dindensis probably had a similar lifestyle, albeit with a less 'specialized' diet.

The ensemble of similarities shared by the modern Aotus and A. dindensis spans two disjunct functional complexes, the masticatory and visual systems. Thus Aotus dindensis is the first fossil platyrrhine to be phyletically linked with living owl monkeys on the basis of morphological and adaptive patterns of high taxonomic weight. Two Patagonian fossil forms are pertinent here. The type specimen of the early Miocene Tremacebus harringtoni jointly shares with Aotus derived features of the orbits as well as the palate ${ }^{12}$, but its dentition is 


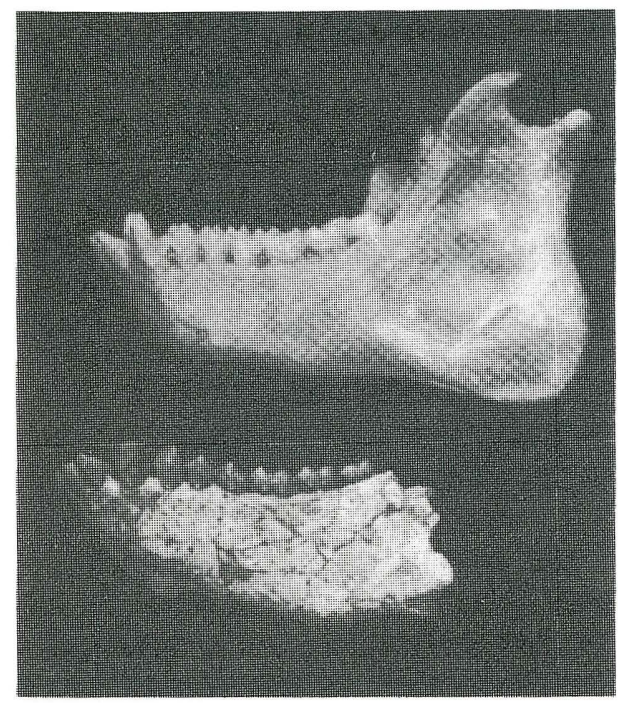

Figure 3 Comparison of Aotus trivirgatus (top) and A. dindensis (below). Buccal view of mandibles $(\times 1.75)$.

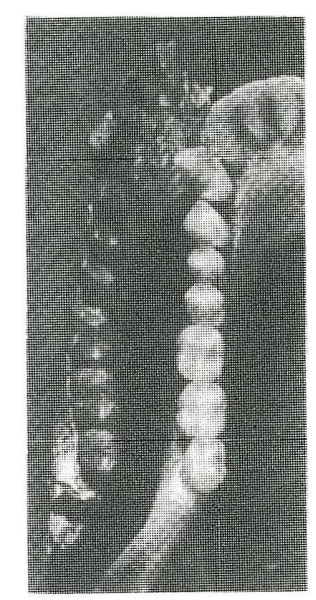

Figure 4 Comparison of Aotus trivirgatus (right) and A. dindensis (left).

poorly preserved and the molar pattern is diflicult to reconstruct and interpret. A mandibular fragment recently allocated to Tremacebus is reportedly most similar to Homunculus ${ }^{13}$, however. The later early Miocene Homunculus, which is known from better material, does not resemble Aotus dindensis in occlusal morphology but is comparable in lateral mandibular profile. However, this pattern is generally primitive for pitheciines ${ }^{14}$, and the cranial anatomy of Homunculus is best interpreted either as evidence of closer affinities with Callicebus ${ }^{12}$, or as primitive pitheciine morphology.

Two other La Venta primates known by excellent dentitions, Neosaimiri fieldsi and Stirtonia tatacoensis, also share extensive similarities with modern forms. They are closely related to Saimiri and to Alouatta, respectively ${ }^{4}$. Among the nonprimate terrestrial mammals, two species are congeneric with the extant murine or mouse opposum, Marmosa ${ }^{15}$, one of the edentates is thought to be directly ancestral to the living giant anteater, Myrmecophaga ${ }^{16}$, and several of the rodents are reportedly very similar and potentially ancestral to modern genera ${ }^{17}$. This association of enduring lineages at La Venta may have important consequences for macroevolutionary interpretations. It suggests that local or regional conditions during the Neogene may have promoted a widespread bathyphyly of the modern indigenous South American mammals, one not limited to the primates. On the other hand, La Venta's larger marsupial ungulates, litopternans, notoungulates, astrapotheres and possibly condylarths left no descendants, just as they became extinct without issue in Patagonia ${ }^{18}$. This makes their loss, thought to be related to the faunal turnover of the great American exchange beginning approximately $8 \mathrm{Myr}^{2} \mathrm{go}^{19}$, even more intriguing.

The discovery that the genus Aotus has a long independent history corresponds with both the principal serological study of New World monkey phylogeny, which postulated an early divergence from the last common ancestor of the platyrrhine radiation ${ }^{20}$, and anatomical studies $^{21}$, which predicted an origin for the lineage well before the middle Miocene. No genus of comparable duration is known among the Old World anthropoids, where Macaca shows the greatest longevity. It is tentatively traceable to the late Miocene, about $8 \mathrm{Myr}$ ago ${ }^{4}$. 
Together with the recent upward revision in the age of the earliest platyrrhine fossil, Branisella boliviana, which at 26-27 Myr (ref. 22) is nearly 10 Myr younger than previously supposed, the confirmation of a bathyphyletic modern radiation raises two basic questions. First, has there been a previous adaptive radiation of New World monkeys during the Paleogene? Second, has the modern radiation ever given rise to a significant collateral branch during the Neogene? Thus the implications of dental similarities shared by Branisella and modern squirrel monkeys ${ }^{1,2,23}$ need to be reconsidered. Although the fossil's occlusal and mandibular structures retain primitive platyrrhine features ${ }^{24}$, nothing precludes Branisella from occupying a phylogenetic position among the modern cebids ${ }^{2}$. The previously established latest date for the origins of this family is $20 \mathrm{Myr}$ ago $^{21}$, marked by the appearance of Dolichocebus gaimanensis, a phyletic link to Neosaimiri and Saimiri ${ }^{3,4}$. The available fossil evidence of platyrrhine evolution, therefore, does not support the contention that the rich diversity of the living forms is a function of the group's remote origin. Rather, it suggests a relatively rapid differentiation following a fairly recent origin, and a degree of taxonomic and morphological stasis which far exceeds the pattern found among Old World primates.

We thank INGEOMINAS of the Republic of Colombia for collaborating with us at La Venta and all the members of our field party. Financial support was by a Grant-in-Aid for Overseas Scientific Survey from the Japanese Government and a US-Japan Cooperative Sciences Program grant to the co-authors.

Reseived 2 December 1986; accepted 6 February 1987.

1. Hershkovitz P. Living New World Monkeys ( Platyrrhini) Vol. I (University of Chicago Press, 1977).

2. Szalay, F. S. \& Delson, E. Evolutionary History of the Primates (Academic, New York, 1979).

3. Rosenberger, A. L. Nature 279, 416-418 (1979).

4. Delson, E. \& Rosenberger, A. L. in Living Fossils (eds Eldredge, N. \& Stanley, S. M.) 50-61 (Springer, New York, 1984).

5. Fields, R. W. Univ. Calif. publs Bull. Dep. Geol. 32, 405-444 (1959).

6. Marshall, L. G. in The Great American Biotic Interchange (eds Stehli, F. G. \& Webb, S. D.) 49-85 (Plenum, New York, 1985).

7. Cartmill, M. in Evolutionary Biology of the New World Monkeys and Continental Drift (eds Ciochon, R. L. \& Chiarelli, A. B.) 243-274 (Plenum, New York, 1980).

8. Wright, P. C. in Ecology and Behavior of Neotropical Primates (eds Coimbra-Filho, A. F. \& Mittermeier, R. A.) 211-240 (Academia Brasileira de Ciencias, Rio de Janeiro, 1981).

9. Kay, R. F. \& Cartmill, M. J. hum. Evol. 6, 19-35 (1977).

10. Schultz, A. H. Am. J. phys. Anthrop. 26, 389-408 (1940).

11. Rathbunn, G. B. Primates 21, 211-219 (1980).

12. Fleagle, J. G. \& Rosenberger, A. L. in Morphologie Evolutive, Morphogenese du Crane et Origine de l'Homme (ed. Sakka, M.) 141-153 (CNRS, Paris, 1983).

13. Fleagle, J. G. \& Bown, T. M. Folia Primatol. 41, 249-266 (1983).

14. Rosenberger, A. L. Phylogeny, Evolution and Classification of New World Monkeys (Platyrrhini, Primates)(University Microfilrns, Ann Arbor, 1979).

15. Marshall, L. G. J. Paleont. 50, 402-418 (1976).

16. Hirschfeld, S. E. J. Paleont. 50, 419-432 (1976).

17. Fields, R. W. Univ. Calif. Publs geol. Sci. 32, 273-404 (1957).

18. Cifelli, R. L. in The Great American Biotic Interchange (eds Stehli, F. G. \& Webb, S. D.) 249-266 (Plenum, New York, 1985).

19. Webb, S. D. in The Great American Biotic Interchange (eds Stehli, F. G. \& Webb, S. D.) 357-386 (Plenum, New York, 1985).

20. Sarich, V. M. \& Cronin, J. R. in Evolutionary Biology of the New World Monkeys and Continental Drift (eds Ciochon, R. L. \& Chiarelli, A. B.) 399-421 (Plenum, New York, 1980). 
21. Rosenberger, A. L. J. hum. Evol. 13, 737-742 (1984).

22. MacFadden, B. J. et al. J. Geol. 93, 223-250 (1985).

23. Wolff, R. G. J. vert. Paleont. 4, 570-574 (1984).

24. Rosenberger, A. L. Int. J. Primatol. 2, 1-7 ( 1981). 